\title{
Knee Skin
}

National Cancer Institute

\section{Source}

National Cancer Institute. Knee Skin. NCI Thesaurus. Code C64859.

The skin of the hinge joint that is located between the thigh and lower leg. 